Revista de
Economia
Contemporâned

\title{
DECOMPOSIÇÃO ESTRUTURAL DA VARIAÇÃO DO EMPREGO NOS SETORES INDUSTRIAIS NO BRASIL ENTRE OS ANOS DE 2000 E 2009
}

\author{
Carina Diane Nakatani-Macedo ${ }^{a}$ \\ Flávio Kauê Fiuza-Moura ${ }^{b}$ \\ Marcia Regina Gabardo da Câmara ${ }^{c}$ \\ Umberto Antonio Sesso Filho ${ }^{d}$ \\ aPrograma de Pós-graduação em Economia Aplicadada Universidade de São Paulo (ESALQ-USP).

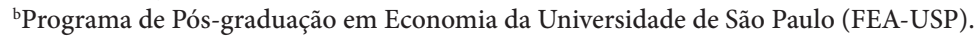 \\ 'Departamento de Economia da UEL. \\ dDepartamento de Economia da UEL.
}

Artigo recebido em 31/01/2015 e aprovado em 24/08/2015.

RESUMO: O objetivo do presente artigo é analisar a variação de emprego nos setores industriais nos anos 2000-2009 para o Brasil. Utiliza-se a metodologia de insumo-produto, através da decomposição estrutural da variação do emprego em efeitos de intensidade, de tecnologia, da demanda, do crescimento e total. Os principais resultados mostraram que entre os dois períodos estudados, houve um acréscimo de 4,39 milhões de vagas para o setor industrial que isoladamente foi responsável por, aproximadamente, $25 \%$ do resultado nacional. Dentre os efeitos estudados pode-se destacar o efeito crescimento e intensidade como principal responsável pelos resultados. Ao considerar o efeito total, os setores que apresentaram maior crescimento relativo no número de empregos foram os de alimentos e bebidas, artigos do vestuário e acessórios e construção civil. Os resultados obtidos permitiram concluir que houve um aumento do número de postos de trabalho para a indústria no Brasil no período analisado, onde a tecnologia, apesar de não explicar unicamente o efeito crescimento, mostra impactos positivos na geração de emprego no efeito total.

PALAVRAS-CHAVE: tecnologia; emprego; insumo-produto; indústria; decomposição estrutural.

CLASSIFICAÇÃO JEL: L60; R15; J20.

Correspondência para: Carina Diane Nakatani-Macedo.

E-mail: nakatanicarina@gmail.com. 


\title{
EMPLOYMENT STRUCTURAL DECOMPOSITION IN MANUFACTURING INDUSTRIES BETWEEN 2000-2009
}

\begin{abstract}
The aim of this article is to analyze the employment variation in manufacturing industries between years 2000-2009 in Brazil. It employs an input-output methodology, by means of employment structural decomposition into intensity, technology, demand, growth and total effects. The main results showed that in the period Brazilian manufacturing sectors added up 4.38 million jobs, which represented $25 \%$ of total jobs created in the country. Among the studied effects, growth and intensity shall be highlighted as the main responsible outcomes. Considering total impacts, the industries that showed greater relative increase in jobs where: food and beverage, clothes and construction. The results lead to the conclusion that, in the studied period, manufacturing in Brazil showed an increase in employment rates, with technology, despite not being the lone factor, having produced a positive impact in job creation.
\end{abstract}

KEYWORDS: technology; employment; input-output; industry; structural decomposition. 


\section{INTRODUÇÃO}

A tecnologia, seu progresso e seus efeitos sobre o mercado de trabalho, principalmente no que tange a níveis de emprego, é objeto de estudo de diversos pesquisadores. Segundo Kato e Ponchirolli (2002), o progresso técnico gera desemprego no primeiro momento, porém, o aumento de produtividade e consequente crescimento econômico devido à evolução tecnológica geram novos postos de trabalho, permitindo a reinserção dos trabalhadores que foram prejudicados em primeira instância. Essa teoria é comumente chamada de "teoria do desemprego por adaptação" ou "desemprego de transição", e vai de encontro aos argumentos normalmente observados entre os pesquisadores da área de Ciências Sociais, que tendem a argumentar que a tecnologia empregada pelo sistema capitalista leva à precarização do homem, à criação de postos secundários de trabalho e à desumanização (Mattoso, 2000; Rossi e Oliveira, 2005).

Nestes termos, faz-se necessário verificar qual a influência do progresso técnico sobre a geração de empregos, quando decomposta por efeito intensidade de uso, arranjo tecnológico, mudança na composição e volume da demanda final. O objetivo da pesquisa é analisar a variação de emprego nos setores industriais nos anos 2000 e 2009 para o Brasil. Utiliza-se a metodologia de insumo-produto, por meio da decomposição estrutural da variação do emprego em efeitos de intensidade, de tecnologia, da demanda, do crescimento e efeito total. O estudo procura medir os efeitos diretos e indiretos que uma elevação do progresso técnico tem sobre a geração de empregos nos setores industriais para o Brasil e realiza-se a decomposição estrutural da variação do emprego no Brasil de 2000 e 2009.

Os anos de 2000 e 2009 foram escolhidos por dois motivos. O primeiro é que, de acordo com o IPEADATA, em 2000 o número de pessoas ocupadas, registradas pelo Censo, foi de aproximadamente 65 milhões, e em 2009 esse número subiu para aproximadamente 86 milhões, resultando num crescimento de algo em torno de $21 \mathrm{mi}$ lhões, o que representa um crescimento de $31,57 \%$ da população ocupada na década. O segundo motivo é a existência de matrizes insumo-produto para tais anos, possibilitando o estudo.

Cacciamali e Bezerra (1997) e De Negri et al. (2006) realizaram estudos relacionando os ganhos de produtividade causados pela abertura comercial com as variações de emprego, e Sesso Filho et al. (2010), Ymai (2010) e Kupfer e Freitas (2004) fizeram uso da metodologia de decomposição estrutural através de matrizes insumo-produto para detectar as fontes da variação do emprego para todos os setores no Brasil para diferentes espaços de tempo. O presente estudo segue a mesma linha dos três últimos mencionados acima, porém, tratando de um novo intervalo de tempo e com enfoque nos setores da indústria. Estudos como este se mostram importantes para que se en- 
tenda o comportamento do emprego nacional quando decompostas suas causas de variação.

Este trabalho está dividido em seis partes, incluindo esta introdução. Na segunda parte será abordada a teoria acerca da relação entre tecnologia e geração de empregos, estabelecendo o debate sobre as duas principais vertentes conflitantes que abordam o assunto, bem como algumas evidências para o caso brasileiro. Na terceira, é abordado o setor industrial no Brasil. Na quarta, será apresentada detalhadamente a metodologia de pesquisa adotada. Na quinta parte será feita a análise tabular dos resultados obtidos. Na sexta e última parte serão apresentadas as conclusões do estudo, suas limitações e possibilidades de estudos futuros.

\section{TECNOLOGIA, PRODUTIVIDADE E (DES)EMPREGO}

Segundo Antunes (2005), desde a era antiga, diversos filósofos discutem acerca da dualidade das características do trabalho, sendo ele fonte de prazer e dor, libertação e escravidão, ânimo e fadiga. Mesmo quando as empresas auferem grandes mudanças tecnológicas em seus sistemas produtivos, reestruturando profundamente o capital, é impossível eliminar todo o trabalho vivo, ou seja, trabalho humano. Porém, a lógica empresarial capitalista dos séculos XX e XXI tem priorizado, em termos microeconômicos, as mudanças técnicas poupadoras de trabalho. Tal lógica, quando aplicada ao quadro geral, conduz à redução do número de pessoas empregadas e, consequentemente, à criação de um mercado secundário de trabalho. Tal mercado apresenta menor remuneração, trabalho terceirizado, não coberto pelas leis trabalhistas. Em termos diretos, empresas de ramos de maior intensidade tecnológica e de progresso técnico mais rápido tendem a apresentar maior participação no processo de precarização do trabalho.

De acordo com Zanella (2006), a tecnologia e seu uso são determinados pela lógica capitalista e esta, por sua vez, é controlada pelo capital. Logo, a produção de mercadorias prioriza o capital, em detrimento do trabalho e do emprego, gerando a precarização do trabalhador. Apesar de tal dinâmica, é importante ressaltar que de acordo com o autor não é o progresso técnico em si que é perverso, mas sim a aplicação capitalista e nada humanizadora dada a ele. A única forma de superar tal sistema seria uma nova forma de organização do trabalho, numa sociedade regida pela lógica do humano, em que seja valorizado o trabalho digno e igualitário.

De acordo com Kato e Ponchirolli (2002), a tecnologia gera um efeito negativo sobre o nível de emprego apenas no curto prazo. Quando o progresso técnico muda a composição setorial e funcional da economia e do emprego ocorre uma espécie de "desemprego transitório de adaptação", que não deve ser necessariamente evitado, mas 
sim administrado através de programas de reinserção e ajuda financeira por parte do governo. A teoria que aborda o "desemprego transitório" afirma que, ao ser inserida uma nova tecnologia poupadora de mão de obra, além de haver demissões por parte das empresas beneficiadas pelo progresso, o ganho de produtividade na economia como um todo leva ao crescimento econômico, que, por sua vez, gera um maior número de empregos. Esse efeito pode ser chamado de "geração de empregos indireta" por parte da evolução técnica.

Segundo Schumpeter apud Mattoso (2000), a inovação tecnológica pode assumir efeito dual sobre o emprego, sendo positiva em momentos de pujança econômica e negativa em casos de baixo crescimento, crise ou até mesmo depressão, fazendo com que as atividades produtivas apareçam num ciclo contínuo de desestruturações e estruturações, criando e destruindo empregos.

Mattoso (2000) afirma que o progresso tecnológico não somente acelera as transformações do trabalho no que tange a sua organização, divisão técnica e qualificação, mas também muda sua distribuição setorial com relação a nascimento e destruição de novas atividades econômicas que, por sua vez, criam e destroem ocupações. Apesar de ser a força motriz desse processo de criação e destruição, o avanço técnico não determina $a$ priori suas consequências quando observado o quadro nacional. Logo, não se pode afirmar que ganhos de produtividade levam a um maior desemprego em todos os casos e em todas as situações.

Segundo Rossi e Oliveira (2005), tecnologia é o conjunto de processos utilizado no sistema produtivo e visa à substituição de trabalho por capital - i.e. progresso técnico poupador de mão de obra. Porém, a "teoria da compensação" afirma que tal efeito negativo direto é compensado, muitas vezes superado, pela geração indireta de empregos causada pelo aumento da produtividade e consequente expansão econômica. Essa teoria ganha base ao se observarem menores taxas de desemprego em economias mais avançadas, quando adotado o ponto de vista tecnológico, e grandes taxas de desemprego em países descapitalizados.

No caso brasileiro, alguns autores analisaram os efeitos do progresso técnico na economia e no desemprego no Brasil. Cacciamali e Bezerra (1997) estudaram os efeitos da abertura comercial entre 1991 e 1995 na indústria nacional e verificaram que os ganhos de produtividade causados pela necessidade de progresso técnico gerado pela abertura comercial foram os grandes causadores do aumento da taxa de desemprego no país. Segundo os autores, é possível concluir que o avanço tecnológico, apesar de causar crescimento, tem sido a força mantenedora do baixo nível de emprego no país nos anos posteriores.

Segundo De Negri et al. (2006), é consenso entre os pesquisadores que a abertura comercial na primeira metade dos anos 1990, cujo efeito foi potencializado na se- 
gunda metade da mesma década em razão da valorização do Real, foi causadora do aumento do desemprego. O aumento é gerado por dois motivos: retirada das firmas menos eficientes do mercado, levando a demissões, e ganhos de produtividade devidos à necessidade de as firmas nacionais se adequarem a fim de atingir níveis de competitividade internacional, sendo este fator mais representativo do que aquele. Tais ganhos de produtividade se deram por meio de reestruturação produtiva ou de importação de insumos (maquinário em geral) tecnologicamente mais avançados, ou seja, que vieram a demandar menor número de trabalhadores enquanto atingiam o mesmo nível de produção. Os autores ainda afirmam que, passada mais de uma década da abertura comercial, os efeitos negativos sobre o emprego não são sentidos na mesma intensidade observada no início de tal processo, corroborando a teoria de desemprego transitório gerado pelo progresso tecnológico. Outra informação digna de nota é que as empresas mais inovadoras e tecnologicamente mais avançadas geraram, entre 2000 e 2004, muito mais emprego do que a geração média observada no mesmo período (De Negri et al., 2006).

Barbosa Filho, Pessoa e Veloso (2010) realizaram um estudo sobre a produtividade total dos fatores (PTF) para a economia brasileira entre os anos de 1992 e 2007. É um trabalho inovador no sentido de considerar o capital humano (anos de estudo do trabalhador e tempo de experiência) no cálculo da PTF. Seus resultados indicaram que o crescimento da produtividade no período foi responsável por apenas 22,9\% do crescimento do volume da demanda. Porém, quando analisados os anos finais do período estudado (2002 a 2007), tal participação sobe para 62,9\%. Tal resultado indica que o crescimento da produtividade, parte dela sob a forma de produtividade da mão de obra, foi uma das principais forças motrizes do crescimento na primeira metade dos anos 2000 .

O trabalho de Pauli, Nakabashi e Sampaio (2012) indica que, após a exacerbada aceleração da taxa de produtividade da indústria entre 1990 e 1999, houve estabilização relativa a partir dos anos 2000 - indicando o fim do choque da abertura comercial. No entanto, não houve substancial aumento na demanda por trabalhadores qualificados na indústria, resultando em excesso de oferta de trabalhadores escolarizados - dirigido pela expansão do ensino público por meio de programas governamentais - e consequente queda nos salários médios.

Tal argumento corrobora os indícios anteriormente encontrados em Ferreira, Ellery Junior e Gomes (2008) e Sampaio, Porcile e Curado (2005), apontando inversão na tendência da produtividade no Brasil a partir dos anos 1990, que vinha caindo desde os anos 1970.

Com relação à produtividade do trabalho, segundo Bonelli e Fontes (2013), esta caiu $0,9 \%$ a.a na década de 1980, apresentou reversão na década de 1990, com cresci- 
mento modesto de 0,7\% a.a., e de 2000 até 2012 apresentou uma média positiva de $1,2 \%$ a.a., sendo a PTF a principal responsável pelo aumento observado na produtividade do trabalho nos anos 2000. Quando observado apenas o período 2006-2011, registra-se um crescimento médio da produtividade do trabalho na ordem de 2,2\% a.a. Apesar do fraco desempenho das produtividades no Brasil a partir dos anos 1980, percebe-se tendência de melhora a partir dos anos 2000.

Também é digna de destaque a conclusão dos autores de que, dada a evolução demográfica, o crescimento das produtividades e o crescimento projetado do PIB, haverá escassez de oferta de mão de obra (PEA insuficiente) para suprir as necessidades produtivas, sendo que entre as possíveis soluções para tal gargalo está a aceleração das taxas de produtividade - entenda-se: maior progresso tecnológico, acima do observado na primeira década do século XXI.

A relação entre tecnologia e emprego nossetores de comércio e serviços foi discutida recentemente no artigo de Fiuza-Moura et al. (2014a), que verificaram que a tecnologia aumentao volume de emprego nesses setores, enquanto que Fiuza-Moura et al. (2014b) verificaram que a tecnologia reduzo volume de emprego na agricultura.

\section{A INDÚSTRIA NO BRASIL}

É inegável, e intensamente discutida na literatura econômica, a importância do setor industrial para o desempenho econômico de qualquer nação.

De acordo com Squeff (2012), um crescimento da indústria impulsionaria o crescimento do produto, uma vez que a produtividade daquela tende a crescer mais rapidamente conforme o produto aumenta (devido às economias de escala do setor manufatureiro), estabelecendo que a lei de Verdoon - que relaciona crescimento da produtividade com crescimento da produção - é dinâmica, ou seja, que a relação se estabelece entre a taxa de variação - crescimento - da produtividade e produto, ao invés de ser uma simples relação causa-efeito entre nível tecnológico e produto.

Conclui-se, portanto, que em muitos casos o crescimento e o desenvolvimento econômico estão fortemente ligados à participação da indústria no produto e emprego do país.

Amorim, Santos e Santos (2010) realizaram um estudo de insumo-produto para o estado do Pará a partir de dados do ano de 2003. No estudo foram encontrados diversos setores industriais como importantes demandantes e fornecedores dos demais setores. Também se encontraram índices multiplicadores de produto, renda e emprego elevados para os setores industriais, principalmente aqueles relacionados com o consumo das famílias, apontando a indústria como setor vital para o dinamismo da economia. 
Em trabalhos como os de Sesso Filho, Rodrigues e Moretto (2007), Sesso Filho et al. (2010), Fachinelli et al. (2011) e Fachinelli et al. (2012) foram encontrados resultados similares, que mostram a importância dos setores industriais no Brasil quando são considerados seus elevados índices de ligações para trás (fortes demandantes de insumos dos demais setores) e elevados índices de ligações para frente (importantes fornecedores de insumos aos demais setores e consumo final). Também indicam, para diversos setores da indústria, altos efeitos multiplicadores de emprego e renda, demonstrando a importância da indústria nacional para o crescimento e desenvolvimento do país.

Na Tabela 1 está a participação no PIB e no pessoal ocupado dos setores industriais para o ano de 2000 e 2009. Os setores discriminados foram aqueles que apresentaram maior participação em um ou outro indicador em pelo menos um dos anos estudados. Os demais setores foram agrupados em "outros" para facilitar a visualização da tabela.

Tabela 1 - Participação no PIB e pessoal ocupado dos setores da indústria brasileira, em 2000 e 2009

\begin{tabular}{lcccc}
\hline \multicolumn{1}{c}{ Setores } & \multicolumn{2}{c}{ Participação no PIB } & \multicolumn{2}{c}{ Participação no pessoal ocupado } \\
\cline { 2 - 5 } & $\mathbf{2 0 0 0}$ & $\mathbf{2 0 0 9}$ & $\mathbf{2 0 0 0}$ & $\mathbf{2 0 0 9}$ \\
\hline Alimentos e bebidas & 2,30 & 2,39 & 2,08 & 2,48 \\
Artigos do vestuário e acessórios & 0,92 & 0,63 & 1,97 & 1,98 \\
Construção & 5,52 & 5,25 & 6,75 & 7,12 \\
Eletricidade e gás, água, esgoto e limpeza urbana & 3,40 & 3,10 & 0,43 & 0,43 \\
Jornais, revistas, discos & 0,92 & 0,71 & 0,44 & 0,41 \\
Móveis e produtos das indústrias diversas & 0,82 & 0,68 & 0,99 & 0,94 \\
Produtos de metal - exclusive máquinas e equipamentos & 0,82 & 1,05 & 0,74 & 0,82 \\
Refino de petróleo e coque & 0,43 & 1,12 & 0,02 & 0,03 \\
Têxteis & 0,82 & 0,55 & 1,05 & 0,96 \\
Outros & 10,20 & 9,52 & 4,74 & 5,07 \\
Total & 26,14 & 25,00 & 19,20 & 20,23 \\
\hline
\end{tabular}

Fonte: Elaboração própria com base em dados de IBGE (2014) e NEREUS (2014).

Os dados da Tabela 1 indicam que, num aspecto geral, os setores industriais apresentaram queda na participação do PIB e aumento em pessoal ocupado no intervalo estudado. Com relação ao PIB dos setores selecionados, apenas alimentos e bebidas e refino de petróleo e coque apresentaram aumentos na participação relativa. No que tange à participação nas ocupações, os setores têxteis, móveis e produtos das indústrias diversas e jornais, revistas e discos apresentaram retrocesso, enquanto os demais ganharam participação relativa, com exceção do setor de eletricidade, gás, água, esgoto e limpeza, que se mostrou estagnado.

A queda da participação do PIB dos setores da indústria foi da magnitude de 4,36\%, sendo que o crescimento de quase 1 ponto percentual do setor de petróleo serviu de amortecimento para esta queda. O crescimento relativo em pessoal ocupado foi de $6,4 \%$. 


\section{METODOLOGIA}

A metodologia de decomposição estrutural tem sido utilizada para identificar as fontes de variação do emprego no Brasil. Sesso Filho et al.(2010) utilizaram a Análise de Decomposição Estrutural para mostrar a variação do emprego no Brasil no período de 1993 a 2003. Os autores verificaram que houve um deslocamento dos postos de trabalho dos setores agropecuário e industrial para comércio e serviços com aumento do número total de pessoas ocupadas em 7,30 milhões. As mudanças foram causadas principalmente pelos efeitos intensidade, com menos 16,62 milhões de vagas, e variação da demanda final, com um aumento de 20,85 milhões de vagas, e com maiores variações entre 1994 e 1995.

Ymai (2010) procurou identificar, por meio da metodologia de análise de decomposição estrutural, as principais fontes de variação no emprego e da renda a partir de 1990 no Brasil. O autor destacou as mudanças ocasionadas pela alteração tecnológica e o impacto desta alteração no emprego. O autor concluiu que a maior parte da variação do emprego e da renda éexplicadaatravés das variações do volume da demanda.

Kupfer e Freitas (2004) analisaram a evolução do emprego no Brasil durante a década de 1990 utilizando o modelo de insumo-produto para decomposição da variação do produto e do emprego e verificaram uma expansão de 5,4 milhões de postos de trabalho na década de 1990. Nesse período os autores constataram que as empresas tiveram que se adaptar ao novo cenário econômico decorrente da maior inserção do país no mercado internacional e também em função do Plano Real, implicando no aumento da produtividade do trabalho e na reestruturação produtiva das empresas, gerada pela concorrência internacional, que levou à queda da demanda por trabalho no geral.

No presente artigo utiliza-se a metodologia de Sesso Filho et al. (2010) e Haan (2001), para realizar a análise de decomposição estrutural e mostrar a variação do emprego no setor de comércio e serviços no Brasil.

Neste capítulo serão descritos resumidamente os principais pontos acerca da metodologia utilizada no artigo. Na primeira parte realiza-se uma breve revisão sobre a teoria básica de insumo-produto segundo alguns principais autores. Na segunda parte apresentam-se informações relacionadas à forma como foram obtidos e tratados os dados, que serão utilizados para a realização da presente pesquisa.

\subsection{INSUMO-PRODUTO: A TEORIA}

Para compreender a teoria de insumo-produto, é necessário realizar a menção de Wassily Leontief - economista russo -, estudioso desta ferramenta. Segundo o autor, é um 
sistema simples, que descreve e serve para interpretar operações econômicas em termos de relações estruturais básicas observáveis.

Segundo Leontief (1983), o esquema insumo-produto deriva da ideia de que cada produto pode ser entendido como um insumo, na medida em que o mesmo é aproveitado em outro setor da cadeia produtiva, dessa forma, compras e vendas são equivalentemente observáveis. Partindo desta afirmação, é possível montar esquemas de entradas e saídas que forneçam informações econômicas instrumentalizáveis. Para Leontief, tal instrumento de estudo gera segurança na medida em que se geram conhecimentos empíricos.

Tal técnica, matriz insumo-produto, que será utilizada neste artigo, é o fundamento central da obra de Leontief. Este método de análise explica o funcionamento de uma economia nacional e de sua estrutura, com objetivo de dar clareza ao planejamento e desenvolvimento econômico.

Em Guilhoto (2000), entende-se que a partir de uma fotografia econômica, obtida por meioda matriz de insumo-produto, pode-se mostrar como os setores estão relacionados entre si, tornando possível compreender quais setores suprem e demandam. Observando tal dinâmica, pode-se compreender como a economia funciona, e como se dá a dependência entre os setores.

Para obter o sistema de insumo-produto, define-se a seguinte equação:

$$
X=(I-D B)^{-1} Y
$$

A equação (1) refere-se ao enfoque setor $(X)$ por setor $(Y)$ com a tecnologia baseada na indústria. Este foco, na tecnologia, é o que mais se aproxima do modelo original de Leontief e, portanto, é o padrão que se costuma utilizar para transformar as matrizes de produção e de usos e recursos no modelo de Leontief. Dada a matriz inversa de Leontief, $L=(I-A)^{-1}$, percebe-se que a matriz $D B$ seria equivalente à matriz $A$ de coeficientes técnicos.

Algumas limitações da análise podem ser apontadas de acordo com os pressupostos em que se baseiam a teoria insumo-produto, entre eles as afirmações de que existe um equilíbrio geral da economia a um dado nível de preços; a inexistência de ilusão monetária dos agentes econômicos; os retornos constantes à escala; os preços constantes; bem como se supõem que as mudanças tecnológicas são lentas; e que todos os bens e serviços incluídos na matriz apresentam uma oferta infinitamente elástica, ou seja, toda a demanda adicional será coberta expandindo-se a produção aos custos representados na matriz (Miernyk, 1974; Guilhoto, 2000). Retornos constantes de escala indicam que as funções são homogêneas. 


\subsection{ANÁLISE DE DECOMPOSIÇÃO}

O objetivo de análise é identificar as causas das variações do emprego em um determinado intervalo de tempo. Duas técnicas são capazes de identificar diversos fatores que influenciam as variáveis econômicas de interesse: a Análise de Decomposição de Índice (Index Decomposition Analysis - IDA) e a Análise de Decomposição Estrutural (Structural Decomposition Analysis - SDA). As duas técnicas se assemelham e podem ser usadas para distinguir como mudanças setoriais, avanços tecnológicos e crescimento econômico provocam variações nas variáveis econômicas e ambientais.

\subsubsection{FORMULAÇÃO MATEMÁTICA DO MODELO ANÁLISE DE DECOMPOSIÇÃO ESTRUTURAL (SDA)}

Wier e Hasler (1999) aplicaram a SDA para a Dinamarca trabalhando com emissões de Nitrogênio e o modelo adotado está descrito abaixo:

$$
N_{t}=w_{t}\left(I-A_{t}\right)^{-1} D_{t} d_{t}
$$

Em (2), $N_{t}$ é um escalar com as emissões de $\mathrm{N}$; $w_{t}$ é um vetor de emissões por unidade de produção; $\left(I-A_{t}\right)^{-1}$ é a matriz inversa de Leontief; $D_{t}$ é a matriz dos componentes da demanda final e $d_{\mathrm{t}}$ é um vetor com o nível absoluto de cada categoria da demanda final. Este modelo é um exemplo de que a metodologia da SDA pode ser aplicada tanto na análise das emissões de $\mathrm{CO}_{2}$, fontes de energia e em pesquisas referentes ao padrão de comércio internacional, estrutura e crescimento da economia e ao mercado de trabalho. O modelo usado por eles é muito semelhante ao adotado por Haan (2001) e que foi empregado neste trabalho. Caso o modelo fosse aplicado para o Brasil com dados de 2009, teríamos que:

$w_{\mathrm{t}}$ é um vetor linha com 55 valores com emissões por unidade de produção dos setores;

$\left(I-A_{t}\right)^{-1}$ é a matriz inversa de Leontief (55x55);

$D_{\mathrm{t}}$ é a matriz dos componentes da demanda final (55x5); e

$d_{\mathrm{t}}$ é um vetor $(5 \mathrm{x} 1)$ com o nível absoluto de cada categoria da demanda final;

já o índice $t$ se refere ao ano de aplicação do modelo e seus dados.

Devido a sua estrutura matemática, a metodologia SDA pode ser utilizada para análise de qualquer informação setorial dada pela matriz de uso, tais como impostos, valor adicionado, importações e salários. 
A decomposição estrutural foi a metodologia empregada por Kupfer e Freitas (2004) para estudar a variação do emprego no país para o período 1990-2001.

A seguir será detalhada a formulação matemática do método SDA que foi utilizada no desenvolvimento deste trabalho. $\mathrm{O}$ modelo que mais atendeu àproposta do artigo é um modelo baseado em Haan (2001) com aplicação ao mercado de trabalho. Os trabalhos que se utilizam do modelo de Análise de Decomposição Estrutural usam o modelo de insumo-produto de Leontief como base para a decomposição, pois este permite uma melhor aproximação da realidade, considerando-se que variações no emprego seguem uma função linear do crescimento econômico.

As mudanças no emprego por setor $(\Delta c)$ podem ser descritas como função do crescimento econômico em termos de ganho ou não de eficiência. Já as mudanças no emprego em termos de unidades monetárias de produto são determinadas por $(\Delta n)$, que significa eficiência do trabalho ou intensidade de emprego. Mudanças nos coeficientes técnicos da economia, mudanças na composição da estrutura da demanda final e o aumento do volume na demanda final podem ser denominadas respectivamente por $(\Delta S),\left(\Delta y^{s}\right)$ e $\left(\Delta y^{v}\right)$. Com isso, a fórmula genérica para cálculo da decomposição dos fatores pode ser caracterizada por:

$$
\Delta c=\Delta n+\Delta s+\Delta y^{s}+\Delta y^{v}
$$

Assim, a decomposição que se refere aos períodos de 2000 e 2009 resulta em quatro diferentes expressões, correspondendo cada uma aos fatores das mudanças estruturais na economia brasileira.

A análise da decomposição estrutural com relação ao número de postos de trabalho pode ser derivada da seguinte forma: suponha que $c_{1 \mathrm{j}}$ de $C$ representa o número de empregos da atividade $j$. Desta maneira, o total de empregos gerados por todas as atividades produtivas pode ser determinado como uma função do produto total:

$$
\mathrm{c}=\mathrm{NX}
$$

O elemento $c$ indica o valor total de empregos gerados em todas as atividades produtivas. O vetor coluna $X$ possui os valores do produto setorial total e $N=C \hat{X}^{-1}$, em que os elementos $n_{1 j}$ de $N$ indicam os coeficientes de emprego, ou seja, a quantidade de empregos gerada por uma unidade monetária de produção da atividade $j . \hat{X}$ representa a matriz diagonalizada de $X$, este é um vetor que possui os valores da produção setorial. A equação $X=(I-A)^{-1}{ }_{y}$ mostra o valor da produçãosetorial total como função da demanda final, sendo que $S=(I-A)^{-1}$ representa a matriz inversa de Leontief e $A$ representa a matriz de coeficientes técnicos. 
O vetor com o total da demanda final, $y$, contém os elementos da demanda final: exportação, consumo das instituições civis sem fins lucrativos, formação bruta de capital fixo, consumo da administração pública e consumo das famílias. Os valores setoriais de variação de estoques foram somados ao consumo das famílias porque o modelo não considera valores negativos, o que pode ocorrer no componente variação de estoques, e este somatório anula possível valores abaixo de zero. Temos cinco componentes da demanda final. O total na linha dessa matriz é o vetor linha $y^{v}$, que é o volume da demanda final com dimensão (1x5). A composição da demanda final, $y$, é uma matriz de coeficientes obtida pela divisão de cada elemento da matriz $E$ pelo vetor $y^{v}$ :

$$
y^{s}=y \hat{y}^{v-1}
$$

Posto isso, os empregos gerados por todas as atividades produtivas podem ser determinados pela seguinte equação:

$$
c=N X=N S y^{s} y^{v}
$$

Em (6), para o caso deste trabalho:

$N$ é o vetor (1x55) de coeficientes de emprego;

$S$ é a matriz (55x55) inversa de Leontief;

$y^{s}$ é a matriz (55x5) de coeficientes da demanda final; e

$y^{v}$ é o vetor (5x1) com o total da demanda final por categoria.

A decomposição estrutural da mudança no uso do fator trabalho e número de empregos entre os períodos de 2000 e 2009 podem ser determinadas como segue:

$$
\begin{aligned}
& \Delta c=c_{(t)}-c_{(t-1)} \\
& \Delta c=N_{(t)} S_{(t)} y_{(t)}^{s} y_{(t)}^{v}-N_{(t-1)} S_{(t-1)} y_{(t-1)}^{s} y_{(t-1)}^{v} \\
& \Delta c=(\Delta N) S_{(t)} y_{(t)}^{s} y_{(t)}^{v}+N_{(t-1)} S_{(t)} y_{(t)}^{s} y_{(t)}^{v}-N_{(t-1)} S_{(t-1)} y_{(t-1)}^{s} y_{(t-1)}^{v} \\
& \Delta c=(\Delta N) S_{(t)} y_{(t)}^{s} y_{(t)}^{v}+N_{(t-1)}(\Delta S) y_{(t)}^{s} y_{(t)}^{v}+N_{(t-1)} S_{(t-1)} y_{(t)}^{s} y_{(t)}^{v}-N_{(t-1)} S_{(t-1)} y_{(t-1)}^{s} y_{(t-1)}^{v} \\
& \Delta c=(\Delta N) S_{(t)} y_{(t)}^{s} y_{(t)}^{v}+N_{(t-1)}(\Delta S) y_{(t)}^{s} y_{(t)}^{v}+N_{(t-1)} S_{(t-1)}\left(\Delta y^{s}\right) y_{(t)}^{v}+N_{(t-1)} S_{(t-1)} y_{(t-1)}^{s} y_{(t)}^{v}-N_{(t-1)} S_{(t-1)} y_{(t-1)}^{s} y_{(t-1)}^{v} \\
& \left.\Delta c=(\Delta N) S_{(t)} y_{(t)}^{s} y_{(t)}^{v}+N_{(t-1)}(\Delta S) y_{(t)}^{s} y_{(t)}^{v}+N_{(t-1)} S_{(t-1)}\left(\Delta y^{s}\right) y_{(t)}^{v}+N_{(t-1)} S_{(t-1)}\right)_{(t-1)}^{s}\left(\Delta y^{v}\right)
\end{aligned}
$$

De acordo com Dietzenbacher e Los (2000), a formulação feita na equação (7) descreve apenas uma situação dentre várias outras possíveis. Desta maneira, com $n$ fatores poderão ocorrer $n$ ! formas de decomposição estrutural, que segue uma estrutura similar à descrita acima. Jacobsen (2000) e Hoem (2003) utilizaram em seus estudos, como resultado de cada componente da decomposição, a média das duas formas polares existentes. A equação (7) é uma das formas polares. A outra é dada por: 


$$
\Delta c=(\Delta N) S_{(t-1)} y_{(t-1)}^{s} y_{(t-1)}^{v}+N_{(t)}(\Delta S) y_{(t-1)}^{s} y_{(t-1)}^{v}+N_{(t)} S_{(t)}\left(\Delta y^{s}\right) y_{(t-1)}^{v}+N_{(t)} S_{(t)} y_{(t)}^{s}\left(\Delta y^{v}\right)
$$

Aqui também é utilizada a sugestão de Jacobsen (2000) e a média das duas formas polares é dada por:

$$
\begin{aligned}
& \Delta c=1 / 2\left((\Delta N) S_{(t)} y_{(t)}^{s} y_{(t)}^{v}+(\Delta N) S_{(t-1)} y_{(t-1)}^{s} y_{(t-1)}^{v}\right) \quad \text { (efeito intensidade de emprego) } \\
& +1 / 2\left(N_{(t-1)}(\Delta S) y_{(t)}^{s} y_{(t)}^{v}+N_{(t)}(\Delta S) y_{(t-1)}^{s} y_{(t-1)}^{v}\right) \quad \text { (efeito tecnológico) } \\
& +1 / 2\left(N_{(t-1)} S_{(t-1)}\left(\Delta y^{s}\right) y_{(t)}^{v}+N_{(t)} S_{(t)}\left(\Delta y^{s}\right) y_{(t-1)}^{v}\right) \quad \text { (efeito estrutura da demanda final) } \\
& +1 / 2\left(N_{(t-1)} S_{(t-1)} y_{(t-1)}^{s}\left(\Delta y^{v}\right)+N_{(t)} S_{(t)} y_{(t)}^{s}\left(\Delta y^{v}\right)\right) \quad \text { (efeito volume da demanda final) }
\end{aligned}
$$

Para obter os resultados desagregados por setor basta tomar $N$ na sua forma diagonalizada na equação (6), $C=\hat{N} x=\hat{N} S y_{(t)}^{s} y_{(t)}^{v}$. Para o presente estudo temos que $t$ se refere ao ano 2009 e $t$ - ao ano 2000.

\subsubsection{FONTES DOS DADOS}

Os dados utilizados neste estudo para compor as matrizes insumo-produto são das Contas Nacionais divulgados pelo Instituto Brasileiro de Geografia e Estatística (IBGE, 2014) do período de 2000 e 2009 e também dados obtidos por meiodos estudos realizados pelo Núcleo de Economia Urbana e Regional da USP (NEREUS, 2014). As matrizes utilizadas possuem 56 setores, mas os cálculos são realizados retirando-se o setor "Serviços domésticos", que apresenta linha e coluna de zeros na matriz de insumo-produto. Este setor refere-se a domicílios que possuem empregados.

\subsubsection{DEFLACIONAMENTO DOS VALORES DAS MATRIZES DE INSUMO-PRODUTO}

O cálculo realizado na decomposição estrutural requer que todos os dados de valores monetários estejam em uma unidade padrão para que os resultados obtidos possam ser comparados ao longo do tempo, excluindo, assim, desvios provocados pelas mudanças monetárias, cortes de zero e variação no nível de preços. Os dados das matrizes são expressos em moeda corrente, portanto, para este trabalho realizou-se a deflação dos dados de 2000 e 2009 adotando-se como ano-base o ano de 2009. O deflator utilizado foi o deflator implícito setorial obtido junto ao IBGE (2009), que traz a variação percentual anual do nível de preços em cada setor. A partir dessa variação elabora-se um índice de preços capaz de transformar todos os valores monetários correntes em 
valores constantes de 2009. Para o deflacionamento basta multiplicar cada valor corrente pelo deflator em índice do setor correspondente.

\section{ANÁLISE DE RESULTADOS}

A Tabela 2 apresenta a decomposição da variação do emprego para os três grandes setores da economia nacional. Para o setor industrial, que apresentou o segundo melhor resultado entre os setores, o efeito intensidade proporcionou um acréscimo de 2.824.766 novas vagas de emprego, já o efeito tecnologia diminuiu com 844 mil vagas, bem como o efeito demanda, que também apresentou uma queda de 1.378.044, que foicompensadapelo efeito proporcionado pelo crescimento, que auferiu um ganho de 3.785.262 vagas, possibilitando um saldo positivo de 4,39 milhões de novas vagas de emprego no total, para este setor, entre os anos de 2000 e 2009.

Tabela 2 - Decomposição estrutural da variação do emprego entre setores no Brasil no período de 2000-2009

\begin{tabular}{lccccc}
\hline \multirow{2}{*}{ Setores } & \multicolumn{5}{c}{ Variação do emprego por tipo de efeito } \\
\cline { 2 - 6 } & Intensidade & Tecnologia & Demanda & Crescimento & Total \\
\hline Setor agrícola e extrativista & -7706 & 1152 & 1911 & 3870 & -773 \\
Setor industrial & 2825 & -844 & -1378 & 3785 & 4388 \\
Setor de comércio e serviços & -502 & 70 & 2946 & 11546 & 14060 \\
Total & -5383 & 378 & 3479 & 19201 & 17675 \\
\hline
\end{tabular}

Nota: $\left(^{*}\right)$ em milhares de empregos.

Fonte: Elaboração própria com base em dados de IBGE (2014) e NEREUS (2014).

A Tabela 3 mostra a decomposição estrutural do emprego para a indústria nacional. O setor industrial apresentou comportamento diferente dos setores de Agricultura e Extrativismo e Comércio e Serviços, com variações a maior para o efeito intensidade de uso do fator e a menor para os efeitos tecnologia e estrutura da demanda (ambos observados de forma inversa nos demais setores).

Os setores da indústria dignos de nota com relação ao efeito intensidade, com viés a menor, foram: Celulose e produtos de papel e Automóveis, camionetas e utilitários, na magnitude de -68 e -67 mil respectivamente. Já aqueles com elevado viés a maior foram: Alimentos e bebidas, Artigos do vestuário e acessórios, Artefatos de couro e calçados, Artigos de borracha e plástico e Construção civil, na magnitude de 244, 776, 353, 211 e 711 respectivamente em milhares. 
Tabela 3 - Decomposição Estrutural da variação do emprego do setor industrial no Brasil no período de 2000-2009

\begin{tabular}{|c|c|c|c|c|c|}
\hline \multirow{2}{*}{ Setores } & \multicolumn{5}{|c|}{ Variação do emprego por tipo de efeito* } \\
\hline & Intensidade & Tecnologia & Demanda & Crescimento & Total \\
\hline 1. Alimentos e bebidas & 244 & 9 & 66 & 437 & 756 \\
\hline 2. Produtos do fumo & -9 & 0 & 8 & 4 & 3 \\
\hline 3. Têxteis & 13 & 28 & -138 & 192 & 96 \\
\hline 4. Artigos do vestuário e acessórios & 776 & -127 & -669 & 379 & 360 \\
\hline 5. Artefatos de couro e calçados & 353 & -48 & -340 & 126 & 92 \\
\hline 6. Produtos de madeira - exclusive móveis & 51 & -27 & -124 & 101 & 2 \\
\hline 7. Celulose e produtos de papel & -68 & 28 & 43 & 40 & 43 \\
\hline 8. Jornais, revistas, discos & 4 & -67 & 31 & 81 & 49 \\
\hline 9. Refino de petróleo e coque & 39 & -21 & -14 & 4 & 8 \\
\hline 10. Álcool & 11 & 18 & 10 & 17 & 57 \\
\hline 11. Produtos químicos & 6 & -19 & 1 & 21 & 9 \\
\hline 12. Fabricação de resina e elastômeros & -10 & 7 & 1 & 5 & 4 \\
\hline 13. Produtos farmacêuticos & -16 & -13 & 23 & 24 & 18 \\
\hline 14. Defensivos agrícolas & 5 & -2 & 1 & 4 & 9 \\
\hline 15. Perfumaria, higiene e limpeza & -32 & -6 & 39 & 23 & 23 \\
\hline 16. Tintas, vernizes, esmaltes e lacas & 15 & -17 & -2 & 7 & 4 \\
\hline 17. Produtos e preparados químicos diversos & 39 & -40 & -10 & 17 & 6 \\
\hline 18. Artigos de borracha e plástico & 211 & -172 & -5 & 80 & 113 \\
\hline 19. Cimento & -6 & 8 & -1 & 3 & 5 \\
\hline 20. Outros produtos de minerais não metálicos & 74 & -28 & -51 & 117 & 113 \\
\hline 21. Fabricação de aço e derivados & 48 & -26 & -12 & 23 & 32 \\
\hline 22. Metalurgia de metais não ferrosos & -1 & 1 & 4 & 24 & 28 \\
\hline $\begin{array}{l}\text { 23. Produtos de metal - exclusive máquinas e } \\
\text { equipamentos }\end{array}$ & 156 & -90 & -11 & 150 & 205 \\
\hline $\begin{array}{l}\text { 24. Máquinas e equipamentos, inclusive manutenção e } \\
\text { reparos }\end{array}$ & 48 & -21 & 89 & 98 & 214 \\
\hline 25. Eletrodomésticos & -2 & -3 & 6 & 11 & 12 \\
\hline 26. Máquinas para escritório e equip. de informática & 0 & 0 & 27 & 8 & 34 \\
\hline 27. Máquinas, aparelhos e materiais elétricos & 90 & -39 & -7 & 44 & 88 \\
\hline 28. Material eletrônico e equipamentos de comunicações & 53 & -26 & -45 & 19 & 1 \\
\hline $\begin{array}{l}\text { 29. Aparelhos/instrumentos médico-hospitalar, medida } \\
\text { e óptico }\end{array}$ & 18 & -9 & 1 & 25 & 36 \\
\hline 30. Automóveis, camionetas e utilitários & -67 & -2 & 68 & 18 & 17 \\
\hline 31. Caminhões e ônibus & -16 & 0 & 16 & 5 & 5 \\
\hline 32. Peças e acessórios para veículos automotores & 72 & -22 & 26 & 58 & 134 \\
\hline 33. Outros equipamentos de transporte & -12 & 11 & 44 & 18 & 61 \\
\hline 34. Móveis e produtos das indústrias diversas & 62 & -54 & -67 & 186 & 127 \\
\hline $\begin{array}{l}\text { 35. Produção e distribuição de eletricidade, gás, água, } \\
\text { esgoto e limpeza urbana }\end{array}$ & -35 & 11 & 12 & 83 & 70 \\
\hline 36. Construção Civil & 711 & -89 & -398 & 1.332 & 1.555 \\
\hline Total & 2.825 & -844 & -1.378 & 3.785 & 4.388 \\
\hline
\end{tabular}

Nota: (*) em milhares de empregos.

Fonte: Elaboração própria com base em dados de IBGE (2014) e NEREUS (2014). 
Para o efeito tecnologia os setores que apresentaram variações a maior foram poucos, sendo os setores de Têxteis e de Celulose e papel os dois maiores, ambos com uma variação na magnitude de 28 mil. Ao mesmo tempo muitos foram os que apresentaram variação a menor, sendo os de Artigos de vestuário e acessório e Artigos de borracha e plástico os com maior variação, na ordem de -127 e -172 mil respectivamente.

Com relação ao efeito estrutura da demanda, os setores com maiores vieses negativos foram os de Têxteis, de Artigos de vestuários e acessórios, Artefatos de couro e calçados, Produtos de madeira - exclusive Móveis e Construção civil, com variação de $-138,-669,-340,-124$ e -398 respectivamente em milhares. Os com maiores vieses positivos foram poucos, com destaque para os setores de Alimentos e bebidas e de Máquinas e equipamentos - inclusive manutenção e reparos, com variações de 66 e 89 mil respectivamente.

Para o efeito crescimento da demanda observam-se vieses positivos em todos os setores, com destaque para os setores de Alimentos e bebidas, Têxteis, Artigos de vestuário e acessórios, Móveis e produtos das indústrias diversas e Construção civil, com variações na magnitude de 437, 192, 379, 186 e 1332, respectivamente em milhares.

O efeito total - líquido - para todos os setores foi positivo, mostrando que o efeito final do progresso técnico para a indústria é benéfico e criador de postos de trabalho, resultado favorável à teoria do emprego transitório por adaptação. Os setores com maior peso para o efeito líquido total - da ordem de 4,39 milhões de ocupações - foram os de Alimentos e bebidas, Artigos do vestuário e acessórios e construção civil com variações de 756, 360 e 1.555, respectivamente, em milhares. Juntos, os três setores foram responsáveis por $60,87 \%$ dos postos de trabalho gerados. Porém, ainda se faz necessário analisar os setores mais a fundo, entendendo quais deles apresentaram maiores ganhos relativos com relação à variação do emprego. Nos gráficos abaixo são mostradas as variações percentuais nos postos de trabalho para todos os setores, entre os anos 2000 e 2009.

O Gráfico 1, em forma de radar, mostra o impacto percentual causado pelo efeito Intensidade nos postos de trabalho dos 36 setores apresentados na Tabela 3 do ano de 2000 para 2009. O centro do gráfico equivale a um impacto negativo de $50 \%$ nos postos de trabalho existentes no ano 2000, enquanto que a fronteira do gráfico indica um impacto positivo de 50\%. A linha circular central indica impacto nulo.

Com base no gráfico vemos que os setores de destaque na geração de empregos são os de números 4 e 36 (Artigos do vestuário e acessórios e Construção civil) com 47,3\% e $43,4 \%$ respectivamente, enquanto os que apresentaram maiores impactos negativos foram os de números 7 e 30 (Celulose e produtos de papel e Automóveis, camionetas e utilitários) com $4,1 \%$ cada. 


\section{Gráfico 1 - Impacto percentual do efeito intensidade sobre os postos de trabalho dos setores industriais no Brasil para o período 2000-2009}

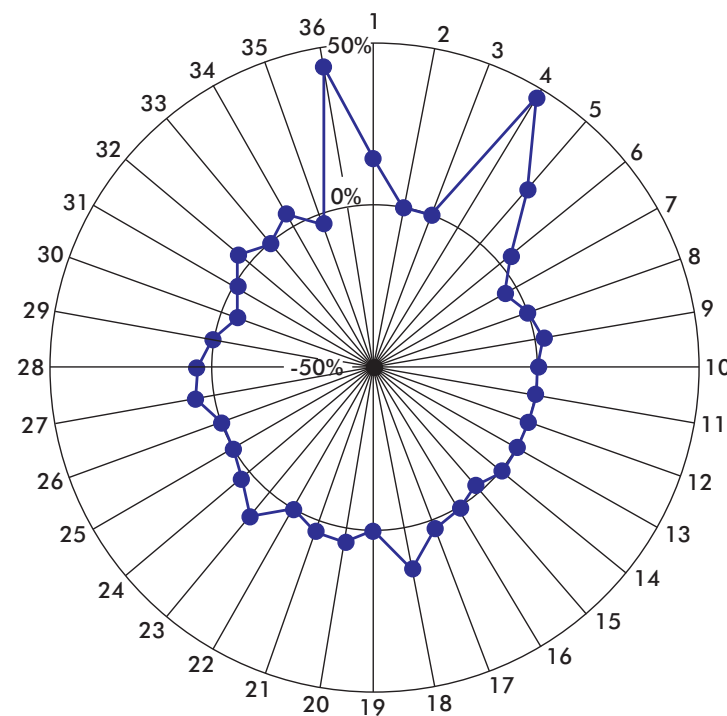

1 - Alimentos e bebidas. 2 - Produtos do fumo. 3 - Têxteis.

4 - Artigos do vestuário e acessórios. 5 - Artefatos de couro e calçados.

6 - Produtos de madeira - exclusive móveis. 7 - Celulose e produtos de papel.

8 - Jornais, revistas, discos . 9 - Refino de petróleo e coque. 10 - Álcool.

11 - Produtos químicos. 12 - Fabricação de resina e elastômeros.

13 - Produtos farmacêuticos. 14 - Defensivos agrícolas.

15 - Perfumaria, higiene e limpeza. 16 - Tintas, vernizes, esmaltes e lacas.

17 - Produtos e preparados químicos diversos. 18 - Artigos de borracha e plástico.

19 - Cimento. 20 - Outros produtos de minerais não metálicos.

21 - Fabricação de aço e derivados. 22 - Metalurgia de metais não ferroso.

23 - Produtos de metal - exclusive máquinas e equipamentos.

24 - Máquinas e equipamentos, inclusive manutenção e reparos.

25 - Eletrodomésticos. 26 - Máquinas para escritório e equip. de informática.

27 - Máquinas, aparelhos e materiais elétricos.

28 - Material eletrônico e equipamentos de comunicações.

29 - Aparelhos/instrumentos médico-hospitalar, medida e óptico.

30 - Automóveis, camionetas e utilitários. 31 - Caminhões e ônibus.

32 - Peças e acessórios para veículos automotores.

33 - Outros equipamentos de transporte.

34 - Móveis e produtos das indústrias diversas.

35 - Produção e distribuição de eletricidade, gás, água, esgoto e limpeza urbana.

36 - Construção civil.

Fonte: Elaboração própria com base em dados de IBGE (2014) e NEREUS (2014).

O Gráfico 2 apresenta o impacto percentual do emprego devido ao efeito Tecnologia e vai de $-200 \%$ a $100 \%$, com duas linhas fronteiriças intermediárias nos valores de $-100 \%$ e $0 \%$. Os setores de destaque positivo para este caso são os de números 10, 12 e 19 (Álcool, Fabricação de resina e elastômeros e Cimento), com impactos de 33,6\%, $31 \%$ e $61,5 \%$, enquanto os setores com destaque negativo foram os de número $9,16,17$ e 18 (Refino de petróleo e coque, Tintas, vernizes, esmaltes e lacas, Produtos e preparados químicos diversos e Artigos de borracha e plástico), com impactos de -131,2\%, $-53,6 \%,-53,1 \%$ e $-55,6 \%$ respectivamente. 


\section{Gráfico 2 - Impacto percentual do efeito tecnologia sobre os postos de trabalho dos setores industriais no Brasil para o período 2000-2009}

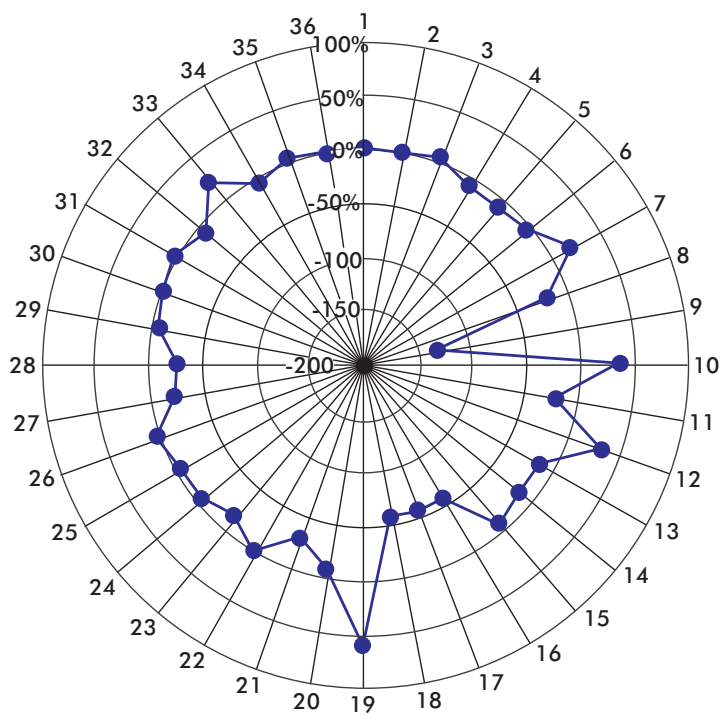

1 - Alimentos e bebidas. 2 - Produtos do fumo. 3 - Têxteis.

4 - Artigos do vestuário e acessórios. 5 - Artefatos de couro e calçados.

6 - Produtos de madeira - exclusive móveis. 7 - Celulose e produtos de papel

8 - Jornais, revistas, discos. 9 - Refino de petróleo e coque. 10 - Álcool.

11 - Produtos químicos. 12 - Fabricação de resina e elastômeros.

13 - Produtos farmacêuticos. 14 - Defensivos agrícolas.

15 - Perfumaria, higiene e limpeza. 16 - Tintas, vernizes, esmaltes e lacas.

17 - Produtos e preparados químicos diversos. 18 - Artigos de borracha e plástico.

19 - Cimento. 20 - Outros produtos de minerais não metálicos.

21 - Fabricação de aço e derivados. 22 - Metalurgia de metais não ferroso.

23 - Produtos de metal - exclusive máquinas e equipamentos.

24 - Máquinas e equipamentos, inclusive manutenção e reparos.

25 - Eletrodomésticos. 26 - Máquinas para escritório e equip. de informática.

27 - Máquinas, aparelhos e materiais elétricos.

28 - Material eletrônico e equipamentos de comunicações.

29 - Aparelhos/instrumentos médico-hospitalar, medida e óptico.

30 - Automóveis, camionetas e utilitários. 31 - Caminhões e ônibus.

32 - Peças e acessórios para veículos automotores.

33 - Outros equipamentos de transporte.

34 - Móveis e produtos das indústrias diversas.

35 - Produção e distribuição de eletricidade, gás, água, esgoto e limpeza urbana.

36 - Construção civil.

Fonte: Elaboração própria com base em dados de IBGE (2014) e NEREUS (2014).

O Gráfico 3 indica o impacto percentual do emprego devido ao efeito Estrutura da Demanda e vai de $50 \%$ a $-50 \%$. Os principais setores geradores de emprego para este efeito são os de números 1, 24 e 30 (Alimentos e bebidas, Máquinas e equipamentos, inclusive manutenção e reparos e Automóveis, camionetas e utilitários) com impactos de $4 \%, 5,4 \%$ e 4,1\%. Já o setores de destaque com relação às reduções relativas de postos de trabalho devido ao efeito Demanda foram os de números 4, 5 e 36 (Artigos do vestuário e acessórios, Artefatos de couro e calçados e Construção Civil), com variação de $-40,8 \%,-20,7 \%$ e $-24,3 \%$. 


\section{Gráfico 3 - Impacto percentual do efeito estrutura da demanda sobre os postos de trabalho dos setores industriais no Brasil para o período 2000-2009}

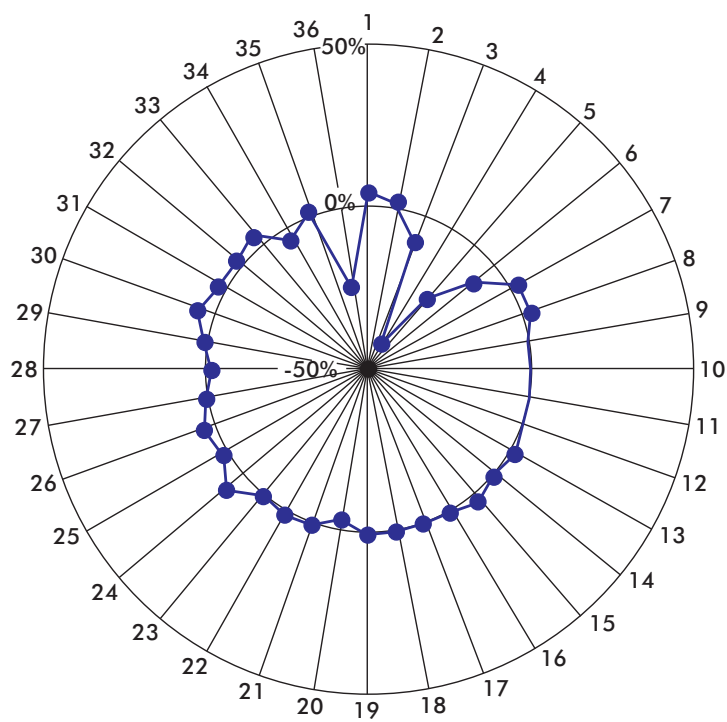

1 - Alimentos e bebidas. 2 - Produtos do fumo. 3 - Têxteis.

4 - Artigos do vestuário e acessórios. 5 - Artefatos de couro e calçados.

6 - Produtos de madeira - exclusive móveis. 7 - Celulose e produtos de papel.

8 - Jornais, revistas, discos. 9 - Refino de petróleo e coque. 10 - Álcool.

11 - Produtos químicos. 12 - Fabricação de resina e elastômeros.

13 - Produtos farmacêuticos. 14 - Defensivos agrícolas.

15 - Perfumaria, higiene e limpeza. 16 - Tintas, vernizes, esmaltes e lacas.

17 - Produtos e preparados químicos diversos. 18 - Artigos de borracha e plástico.

19 - Cimento. 20 - Outros produtos de minerais não metálicos.

21 - Fabricação de aço e derivados. 22 - Metalurgia de metais não ferroso.

23 - Produtos de metal - exclusive máquinas e equipamentos.

24 - Máquinas e equipamentos, inclusive manutenção e reparos.

25 - Eletrodomésticos. 26 - Máquinas para escritório e equip. de informática.

27 - Máquinas, aparelhos e materiais elétricos.

28 - Material eletrônico e equipamentos de comunicações.

29 - Aparelhos/instrumentos médico-hospitalar, medida e óptico.

30 - Automóveis, camionetas e utilitários. 31 - Caminhões e ônibus.

32 - Peças e acessórios para veículos automotores.

33 - Outros equipamentos de transporte.

34 - Móveis e produtos das indústrias diversas.

35 - Produção e distribuição de eletricidade, gás, água, esgoto e limpeza urbana.

36 - Construção civil.

Fonte: Elaboração própria com base em dados de IBGE (2014) e NEREUS (2014).

O Gráfico 4 indica o impacto percentual de empregos de 2000 a 2009 devido ao efeito Crescimento da Demanda, indo de $80 \%$ a $-80 \%$. Dentre todos os setores industriais nenhum apresentou impactos negativos no volume de emprego para este caso. Os principais com impacto positivo foram os de números 1, 4, 34 e 36 (Alimentos e bebidas, Artigos do vestuário e acessórios, Móveis e produtos das indústrias diversas e Construção Civil) com impacto de 26,7\%, 23,1\%, 11,3\% e 81,2\%, respectivamente. 


\section{Gráfico 4 - Impacto percentual do efeito volume da demanda sobre os postos de trabalho dos setores industriais no Brasil para o período 2000-2009}

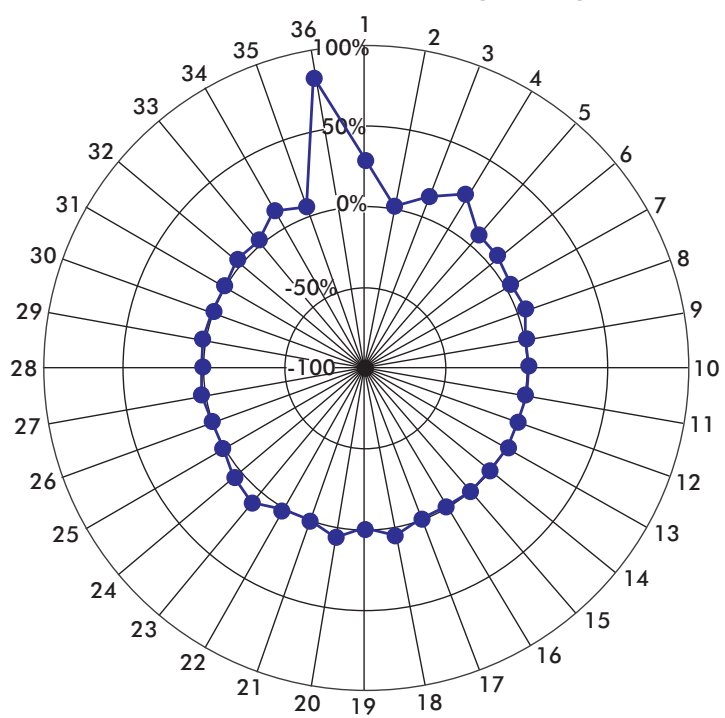

1 - Alimentos e bebidas. 2 - Produtos do fumo. 3 - Têxteis.

4 - Artigos do vestuário e acessórios. 5 - Artefatos de couro e calçados.

6 - Produtos de madeira - exclusive móveis. 7 - Celulose e produtos de papel.

8 - Jornais, revistas, discos. 9 - Refino de petróleo e coque. 10 - Álcool.

11 - Produtos químicos. 12 - Fabricação de resina e elastômeros.

13 - Produtos farmacêuticos. 14 - Defensivos agrícolas.

15 - Perfumaria, higiene e limpeza. 16 - Tintas, vernizes, esmaltes e lacas.

17 - Produtos e preparados químicos diversos. 18 - Artigos de borracha e plástico.

19 - Cimento. 20 - Outros produtos de minerais não metálicos.

21 - Fabricação de aço e derivados. 22 - Metalurgia de metais não ferroso.

23 - Produtos de metal - exclusive máquinas e equipamentos.

24 - Máquinas e equipamentos, inclusive manutenção e reparos.

25 - Eletrodomésticos. 26 - Máquinas para escritório e equip. de informática.

27 - Máquinas, aparelhos e materiais elétricos.

28 - Material eletrônico e equipamentos de comunicações.

29 - Aparelhos/instrumentos médico-hospitalar, medida e óptico.

30 - Automóveis, camionetas e utilitários. 31 - Caminhões e ônibus.

32 - Peças e acessórios para veículos automotores.

33 - Outros equipamentos de transporte.

34 - Móveis e produtos das indústrias diversas.

35 - Produção e distribuição de eletricidade, gás, água, esgoto e limpeza urbana.

36 - Construção civil.

Fonte: Elaboração própria com base em dados de IBGE (2014) e NEREUS (2014).

O Gráfico 5 relaciona a variação percentual líquida do emprego nos setores industriais para o período estudado. Observa-se que apesar de alguns setores terem sofrido com impactos negativos no número de postos de trabalho, quando observados os efeitos separados, nenhum setor apresentou variação negativa ao se considerar o efeito total líquido. Os setores de destaque, com maiores variações relativas, foram os de números 1, 4, e 36 (Alimentos e bebidas, Artigos do vestuário e acessórios e Construção Civil), com variações de 46,1\%, 22\% e 94,8\%, respectivamente. Os setores que se mostraram menos sensíveis, com menores variações, foram os de números 2, 6, 12, 28 
e 31 (Produtos do fumo, Produtos de madeira - exclusivemóveis, Fabricação de resina e elastômeros, Material eletrônico e equipamentos de comunicações e Caminhões e ônibus), com variações de $0,2 \%, 0,1 \%, 0,2 \%, 0,1 \%$ e $0,3 \%$, respectivamente.

\section{Gráfico 5 - Variação percentual dos postos de trabalho para os setores industriais no Brasil para o período 2000-2009}

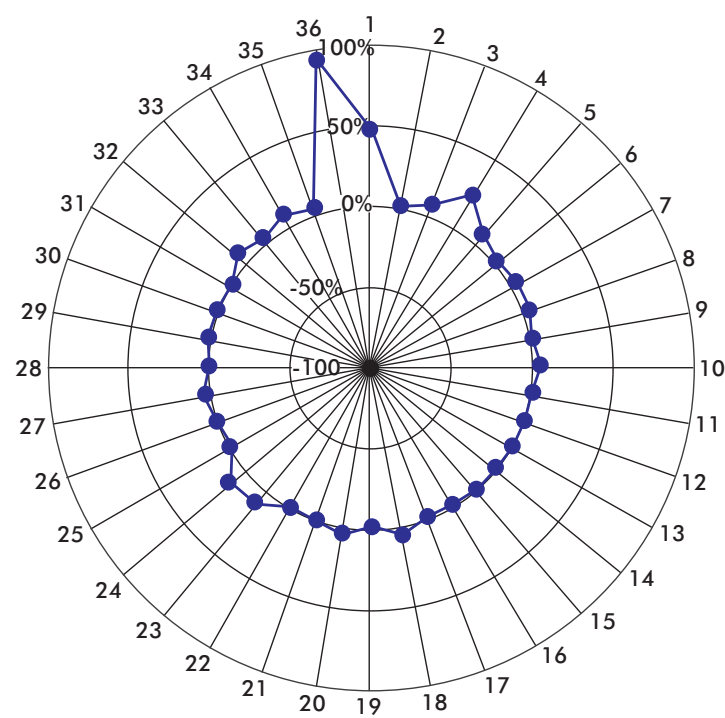

1 - Alimentos e bebidas. 2 - Produtos do fumo. 3 - Têxteis.

4 - Artigos do vestuário e acessórios. 5 - Artefatos de couro e calçados.

6 - Produtos de madeira - exclusive móveis. 7 - Celulose e produtos de papel

8 - Jornais, revistas, discos. 9 - Refino de petróleo e coque. 10 - Álcool.

11 - Produtos químicos. 12 - Fabricação de resina e elastômeros.

13 - Produtos farmacêuticos. 14 - Defensivos agrícolas.

15 - Perfumaria, higiene e limpeza. 16 - Tintas, vernizes, esmaltes e lacas.

17 - Produtos e preparados químicos diversos. 18 - Artigos de borracha e plástico.

19 - Cimento. 20 - Outros produtos de minerais não metálicos.

21 - Fabricação de aço e derivados. 22 - Metalurgia de metais não ferroso.

23 - Produtos de metal - exclusive máquinas e equipamentos.

24 - Máquinas e equipamentos, inclusive manutenção e reparos.

25 - Eletrodomésticos. 26 - Máquinas para escritório e equip. de informática.

27 - Máquinas, aparelhos e materiais elétricos.

28 - Material eletrônico e equipamentos de comunicações.

29 - Aparelhos/instrumentos médico-hospitalar, medida e óptico.

30 - Automóveis, camionetas e utilitários. 31 - Caminhões e ônibus

32 - Peças e acessórios para veículos automotores.

33 - Outros equipamentos de transporte.

34 - Móveis e produtos das indústrias diversas.

35 - Produção e distribuição de eletricidade, gás, água, esgoto e limpeza urbana.

36 - Construção civil.

Fonte: Elaboração própria com base em dados de IBGE (2014) e NEREUS (2014). 


\section{CONSIDERAÇÕES FINAIS}

O presente estudo permitiu demonstrar que, apesar de alguns teóricos afirmarem que a tecnologia gera precarização do trabalho humano, substituindo-o por maquinário, a tecnologia, em seu efeito final, pode, mesmo considerando a existência de outros fatores que impactem no efeito volume da demanda, levar à criação líquida de postos de trabalho. A análise dos três grandes setores da economia de forma agregada permite observar que os setores industriais foram responsáveis por, aproximadamente, $25 \%$ do total de empregos gerados entre 2000 e 2009.

Para a análise agregada no setor industrial observa-se o efeito intensidade como um dos principais geradores de postos de trabalho, fenômeno que pode ser explicado pela elevada qualificação da mão de obra utilizada e consequente alta produtividade marginal.

Os setores que se destacaram de forma positiva para o efeito intensidade foram os de artigos do vestuário e acessórios e construção civil. Com destaque em redução de postos de trabalho estão os setores de celulose e produtos de papel e automóveis, camionetas e utilitários.

Já para o efeito tecnologia, os principais setores para a geração de postos de trabalho foram os de álcool, fabricação de resina e elastômeros e cimento. Enquanto que aqueles com maior efeito negativo foram os de refino de petróleo e coque, tintas, vernizes, esmaltes e lacas, produtos e preparados químicos diversos e artigos de borracha e plástico.

O efeito estrutura da demanda teve como setores-chave na geração de empregos os de alimentos e bebidas, máquinas e equipamentos, inclusive manutenção e reparos de automóveis, camionetas e utilitários, enquanto os setores de artigos do vestuário e acessórios, artefatos de couro e calçados e construção civil apresentaram as maiores reduções nos postos de trabalho.

No efeito volume da demanda, além de ocorrerem as maiores variações absolutas, não houve variações negativas, e os principais setores criadores de ocupações são: alimentos e bebidas, artigos do vestuário e acessórios, móveis e produtos das indústrias diversas e construção civil.

Ao considerar o efeito total, nenhum setor apresentou queda líquida no número de ocupações, impulsionados principalmente pelos efeitos intensidade e crescimento da demanda. Os setores que apresentaram maior crescimento relativo no número de empregos foram os de alimentos e bebidas, artigos do vestuário e acessórios e construção civil. Aqueles com menores taxas de crescimento nos postos de trabalho foram os de produtos do fumo, produtos de madeira - exclusive Móveis, Fabricação de resina e elastômeros, Material eletrônico e equipamentos de comunicações e Caminhões e ônibus. 
Os resultados obtidos permitem concluir que a tecnologia, apesar de no curto prazo gerar desemprego em alguns setores no Brasil no período analisado, levou à criação de um maior número de postos de trabalho. É válido ressaltar que a criação de empregos decorrente de progresso técnico não ocorre, necessariamente, no setor cujo crescimento tecnológico foi observado, podendo se realizar em outros segmentos da economia. Também é necessário ressaltar que tal geração de empregos no longo prazo não implica, necessariamente, em emprego melhores ou mais bem remunerados. Novos estudos devem ser realizados para que cada um dos setores seja estudado em separado, com o intuito de entender a dinâmica do emprego em setores selecionados da economia brasileira e a sua relação com as mudanças tecnológicas.

\section{REFERÊNCIAS}

AMORIM, A. L.; SANTOS, R. B. N. dos; SANTOS, F. T. P. D. Análise das relações intersetoriais da economia paraense e seus efeitos multiplicadores. In: Congresso da Sociedade Brasileira de Economia, Administração e Sociologia Rural (SOBER), 48, Campo Grande, MS, 2010. Anais... 2010, p. 01-21.

ANTUNES, R. O caracol e sua concha: ensaios sobre a nova morfologia do trabalho. [On-line] Boitempo Editorial, 2005. Disponível em: <http://books.google.com.br/books?hl=ptBR\& $\mathrm{lr}=\& \mathrm{id}=4 \mathrm{~d} \_$XspEYAkAC\&oi=fnd\&pg=PA11\&dq=Tecnologia,+trabalho+e+desemprego:+ um+conflito+social\&ots=LpH2X8te89\&sig=IB5zEnUotxI6u2TujEGoMyqi9cQ\#v=onepag e\&q\&f=false $>$. Acesso em: 7 out. 2013.

BARBOSA FILHO, F. H.; PESSOA, S. A.; VELOSO, F. A. Evolução da produtividade total dos fatores na economia brasileira com ênfase no capital humano - 1992-2007. Revista Brasileira de Economia, v. 64, n. 2, jun. 2010.

BERNARDES, R.; BESSA, V.; KALUP, A. Serviços na Paep 2001: reconfigurando a agenda de pesquisas estatísticas inovação. São Paulo em Perspectiva, v. 19, n. 2, p. 115-134, abr./jun. 2005 .

BONELLI, R.; FONTES, J. Desafios brasileiros no longo prazo. Texto para Discussão, FGV/ IBRE, 2013. Disponível em: <http://iepecdg.com.br/uploads/artigos/Desafios\%20Brasileiros\%20no\%20Longo\%20Prazo\%20-\%2028_05_2013.pdf>. Acesso em: 14 jul. 2014

CACCIAMALI, M.C.; BEZERRA, L.L. Produtividade e emprego industrial no Brasil. Revista Brasileira de Economia, v. 51, n. 1, 1997.

DE NEGRI, J. A.; DE NEGRI, F.; COELHO, D. (Ed.) Tecnologia, exportação e emprego. Rio de Janeiro: IPEA, 2006. Disponível em: <http://www.ipea.gov.br/agencia/images/stories/ PDFs/livros/Cap_1.pdf>. Acesso em: 21 nov. 2013.

DIETZENBACHER, E.; LOS, B. Structural decomposition analysis with dependent determinants. In: Conference on Input Output Techniques, 13, 2000, Macerata. Anais Eletrônicos... Macerata, 2000. Disponível em: <http://policy.rutgers.edu/cupr/iioa/iioa.htm >. Acesso em: 30 nov.2013. 
FACHINELLI, A. S.; MARGONATO, R. C. G.; LOPES, R. L.; RODRIGUES, L. R.; SESSO FILHO, U. A. Distribuição inter-regional do emprego e da renda: uma análise de insumoproduto para a Região Sul e o restante do Brasil. In: Encontro Nacional da Associação de Estudos Regionais e Urbanos, 9, Natal, 2011.

FACHINELLI, A. S.; RODRIGUES, L. R.; SESSO FILHO, U. A.; MORETTO, A. C.; GUILHOTO, J. J. M. Multiplicador de emprego e salário: estudo comparativo para a região sul e restante do Brasil em 1999 e 2004. In: ANPEC SUL, 2012, Porto Alegre, 2012.

FERREIRA, P. C.; ELLERY JR., R.; GOMES, V. Produtividade agregada brasileira (1970-2000): declínio robusto e fraca recuperação. Estud. Econ., v. 38, n. 1, mar. 2008.

FIUZA-MOURA, F. K.; NAKATANI-MACEDO, C. D.; CAMARA, M. R. G.; SESSO FILHO, U. A. Decomposição estrutural da variação do emprego: Comércio e serviços no Brasil entre os anos de 2000 e 2009. In: Encontro de Economia Paranaense, 11, 2014a.

FIUZA-MOURA, F. K.; NAKATANI-MACEDO, C. D.; CAMARA, M. R. G.; SESSO FILHO, U. A. Decomposição estrutural da variação do emprego nos setores Agricultura e extrativismo no Brasil entre os anos de 2000 e 2009: A Tecnologia gera desemprego? In: Encontro de Economia da Região Sul -ANPECSUL, 17, Maringá, 2014. Anais... Maringá: EDUEM, v. 1, p. 1-20, $2014 \mathrm{~b}$.

GUILHOTO, J. J. M.; Análise de insumo-produto: teoria e fundamentos. Texto para Discussão, Departamento de Economia, Administração e Sociologia, Escola Superior de Agricultura "Luiz de Queiroz" - USP, 2000.

HAAN, de M. A structural decomposition analysis of pollution in the Netherlands. Economic Systems Research, v. 13, n. 2, p. 181-196, jun. 2001.

HIDALGO, A. B.; MATA, D. Produtividade e desempenho exportador das firmas na indústria de transformação brasileira. Estud. Econ., v. 39, n. 4, dez. 2009

HOEM, A. A decomposition analysis of the emissions of $\mathrm{CO}_{2}$. In: European Congress of the Regional Science Association, 43, 2003, Jyväskylä. Anais Eletrônicos... Jyväskylä, 2003. Disponível em:<www.jyu.fi/ersa2003/>. Acesso em: 27 out. 2013.

IBGE. INSTITUTO BRASILEIRO DE GEOGRAFIA E ESTATÍSTICA. Contas Nacionais: Brasil, 2000-2009. [On-line] IBGE, 2013. Disponível em: <http://www.ibge.gov.br> Acesso em: 25 out. 2013.

IBGE. INSTITUTO BRASILEIRO DE GEOGRAFIA E ESTATÍSTICA. Matriz de insumo-produto: Brasil, 1985/1990-1996. [On-line] IBGE, 2013. Disponível em: <http://www.ibge.gov. br>. Acesso em: 25 out. 2013.

IBGE. INSTITUTO BRASILEIRO DE GEOGRAFIA E ESTATÍSTICA. Sistema de Contas Nacionais - 2009. Banco de Dados. [On-line] IBGE, 2013.Disponível em <www.ibge.gov.br>. Acesso em: 25 out. 2013.

JACOBSEN, H. K. Energy demand, structural change and trade: A decomposition analysis of the Danish manufacturing industry. Economic Systems Research, v. 12, n. 3, p. 319-343, Sept. 2000.

KATO, J. M.; PONCHIROLLI, O. O desemprego no Brasil e os seus desafios éticos. Revista da $F A E$, v. 5, n. 3, p. 87-97, 2002. 
KUPFER, D.; FREITAS, F. Análise estrutural da variação do emprego no Brasil entre $1990 \mathrm{e}$ 2001. Boletim de Conjuntura, Instituto de Economia da UFRJ, Rio de Janeiro, p. 1-6, mar. 2004.

LEONTIEF, W. Input-Output Economics. 2 ed. New York: Oxford University Press. 1983.

MATTOSO, J. Tecnologia e emprego: uma relação conflituosa. São Paulo Perspec., v. 14, n. 3, jul. 2000. Disponível em: <http://www.scielo.br/scielo.php?script=sci_arttext\&pid=S0102$-88392000000300017 \& \operatorname{lng}=\mathrm{en} \& \mathrm{nrm}=\mathrm{iso}>$. Acesso em7 out. 2013.

MIERNYK, W. H. Elementos de análise do insumo-produto. São Paulo: Atlas, 1974.

PAULI, R. C.; NAKABASHI, L.; SAMPAIO, A. V. Mudança estrutural e mercado de trabalho no Brasil. Rev. Econ. Polit., v. 32, n. 3, set. 2012.

ROSSI, T.; OLIVEIRA, E. A. A. Q. A questão do desemprego no Brasil. In: IX Encontro Latino Americano de Iniciação Científica e V Encontro Latino Americano de Pós-Graduação, 2005. Disponível em: <http://biblioteca.univap.br/dados/INIC/cd/inic/IC6\%20anais/IC6-115. PDF>. Acesso em: 7 out. 2013.

SESSO FILHO, U. A.; RODRIGUES, R. L.; MORETTO, A. C. Decomposição do efeito multiplicador de produção e emprego no sistema inter-regional Sul-Restante do Brasil. In: Encontro de Economia Paranaense, 5, Curitiba, 2007.

SESSO FILHO, U. A.; RODRIGUES, R. L.; MORETTO, A. C.; BRENE, P. R. A.; LOPES, R. L. Decomposição estrutural da variação do emprego no Brasil, 1991-2003. Economia Aplicada, v. 14, p. 99-123, 2010.

SQUEFF, G. C. Desindustrialização: luzes e sombras no debate brasileiro. Texto para Discussão, Rio de Janeiro, IPEA, n. 1747, 2012.

WIER, M.; HASLER, B. Accounting for nitrogen in Denmark: a structural decomposition analysis. Ecological Economics, v. 30, n. 2, p. 317-331, Aug. 1999.

YMAI, A. K.Decomposição estrutural do emprego e da renda no Brasil: Uma análise de insumoproduto - 1990 a 2007. Dissertação de Mestrado, Programa de Pós-Graduação em Economia Regional, Universidade Estadual de Londrina, Londrina, 2010.

ZANELLA, J. L. O trabalho concreto diante das máquinas: seriam as máquinas as causadoras do desemprego? Revista Faz Ciência, v. 8, n. 1, 2006. Disponível em: <http://e-revista.unioeste. br/index.php/fazciencia/article/viewArticle/347> . Acesso em 9 out. 2013. 